\title{
Assessment of Caries Index and Fluoride Intake in a Pediatric Middle Eastern Population
}

\author{
Zoukaa El Mir ${ }^{1}$, Nada El Osta ${ }^{2}$, Michel Salameh ${ }^{3}$, Radwan Massoud ${ }^{4}$, Lionel El Haddad ${ }^{5}$, Nada Farhat Mchayleh ${ }^{6}$
}

\begin{abstract}
Aims: To assess the fluoride concentration in water sources and its association with caries index in children living in Tripoli, Lebanon. Materials and methods: The concentration of fluoride was measured in tap and bottled water using ion chromatography. For tap water, eight water sources were evaluated before and after domestic distribution during June and November 2016. For bottled water, seven brands available on the market were tested. Caries were recorded in 402 children using DMFT/dmft indices. A questionnaire was distributed to parents to gather information about sociodemographic characteristics, the source of water consumed, the consumption of fluoride supplements, fluoridate salt, tea and sweets, and the frequency of toothbrushing.

Results: The fluoride concentration in tap water was not significantly different from the optimal concentration $(p$ value $>0.05)$. However, the amount of fluoride in bottled water $(0.14 \pm 0.698 \mathrm{mg} / \mathrm{L})$ was significantly lower than the optimal amount of fluoride recommended by the World Health Organization for decay prevention $(0.5-1 \mathrm{mg} / \mathrm{L})(p$ value $<0.001)$. The prevalence of caries was elevated in children aged 5 years $(90.5 \%)$ and 12 years (89.6\%). The carious indices were lower in children who consume tap water, tea, and fluoridated salt and those who consume less sweet.

Conclusion: Additional studies covering all Lebanese regions should be performed to develop a national policy concerning fluoride-based scientific evidences.

Clinical significance: Pedodontists should take in consideration the source of water consumed by the patient before prescribing a fluoride supplementation to avoid an overconsumption. They should promote effective oral hygiene methods and nutritional education and encourage regular tea consumption as an affordable source of fluoride to prevent caries.

Keywords: Children, Decay missed filled tooth, Fluoride, lon chromatography, Source of water.

The Journal of Contemporary Dental Practice (2020): 10.5005/jp-journals-10024-2945
\end{abstract}

\section{INTRODUCTION}

Dental caries is a public health concern; it reduces quality of life by causing infection, pain, and tooth loss.' In children, tooth decay can cause chewing, phonation, and sleep problems, limiting daily activities and learning. ${ }^{2}$ Fluoride remains the most effective preventive measure against tooth decay. It has several beneficial effects on oral health due to its action on dental tissues and on the cariogenic bacteria. On the one hand, it inhibits demineralization by increasing the resistance of dental tissues against acid attacks and promotes their remineralization, and on the other hand, it inhibits bacterial metabolism and plaque formation. ${ }^{3}$ Water fluoridation is the most widely used public health policy in the world for caries prevention. ${ }^{4}$ It is still considered as cost-effective and essential policy in the 21st century in the prevention of dental caries at the community level. ${ }^{5}$ Nevertheless, one should be aware of the side effects of excessive exposure, such as dental fluorosis. Public health authorities must balance fluoride intake to prevent dental caries while minimizing dental fluorosis. Therefore, systemic exposure to fluoride must be assessed prior to the introduction of a communitywide fluoridation program. ${ }^{6}$

According to World Health Organization (WHO), Lebanon is a small Middle Eastern country that has one of highest "decay missed filled tooth" (DMFT) index (>4.4) in the world for 12-year-olds. ${ }^{7}$ Another recent nationwide study still shows a high prevalence of tooth decay among children of different age. ${ }^{8}$ This puts Lebanon among the countries most concerned in the fight against carious disease. Despite these imminent needs, fluoridation of water and salt remains a matter of national debate. The last assessment of fluoride levels in water in Lebanon dates to $2004^{9}$ and showed low
1,3,6 Department of Pediatric Dentistry, Faculty of Dental Medicine, Saint Joseph University of Beirut, Lebanon

${ }^{2}$ Department of Prosthodontics, Faculty of Dental Medicine, Saint Joseph University of Beirut, Lebanon; University of Clermont Auvergne, EA 4847, Centre de Recherche en Odontologie Clinique, ClermontFerrand, France; Laboratoire de Recherche Craniofaciale, Unité de Santé Orale, Faculty of Dental Medicine, Saint Joseph University of Beirut, Lebanon

${ }^{4}$ Department of Internal Medicine, American University of Beirut Medical Center, Beirut, Lebanon

${ }^{5}$ Department of Industrial Technology, Faculty of Science, Saint Joseph University of Beirut, Lebanon

Corresponding Author: Nada El Osta, Department of Prosthodontics, Faculty of Dental Medicine, Saint Joseph University of Beirut, Lebanon; University of Clermont Auvergne, EA 4847, Centre de Recherche en Odontologie Clinique, Clermont-Ferrand, France; Laboratoire de Recherche Craniofaciale, Unité de Santé Orale, Faculty of Dental Medicine, Saint Joseph University of Beirut, Lebanon, Phone: +961 70 716252, e-mail: pronada99@hotmail.com

How to cite this article: El Mir Z, El Osta N, Salameh M, et al. Assessment of Caries Index and Fluoride Intake in a Pediatric Middle Eastern Population. J Contemp Dent Pract 2020;21(10):1098-1104.

Source of support: The study was funded by a grant from Saint Joseph University Research Council (FMD146).

Conflict of interest: None

levels of fluoride in all water sources except few sources, including the city of Tripoli. At the same time, data on fluoride exposure from 
food are limited..$^{10}$ This prompted us to conduct this study with the first objective to evaluate fluoride concentrations in all water sources in the city of Tripoli. The second objective was to assess factors associated with caries indices DMFT/dmft in a population of children aged 5 years and 12 years living in different socioeconomic regions of Tripoli. These factors included the daily toothbrushing, the sweet consumption, the source of water consumed, the fluoride supplements intake, the fluoride salt intake, and the consumption of tea.

\section{Materials and Methods}

\section{Study Design}

This was an exploratory, descriptive, and cross-sectional study conducted in Tripoli, Lebanon. The protocol of the study was approved by the Ethics Committee of Saint Joseph University of Beirut (USJ-2017-127), the "National Water of North Lebanon" the governmental entity responsible for water management in North Lebanon, and the Lebanese Ministry of National Education. Written informed consent in accordance with the declaration of Helsinki was obtained from the parents of the participants, and verbal informed assent was also obtained from the children.

\section{Assessment of Fluoride Concentrations}

The assessment of fluoride concentrations was performed in tap and bottled water. According to National Water of North Lebanon, there are eight main sources in Tripoli. For each source, one or two distribution points were randomly selected to assess fluoride concentration in tap water before and after home distribution. Three samples were taken from each source (63 samples in total). Each source was evaluated twice (June and November 2016). For each collection a $500-\mathrm{mL}$ plastic bottle was washed three to four times with water from the source to be measured and then filled and sealed. Each bottle was labeled with the date, time, and source of collection. Samples were then placed in suitable containers and immediately transported to the designated lab for analysis. Seven available brands of bottled water brands on the market were tested: 3 bottles $(500 \mathrm{~mL}$ ) of each brand of different batches (total 27 bottles) were randomly selected for testing at the same lab as the tap water. The chemical analysis was conducted using the Waters ion chromatography (IC) technique as described by WHO. ${ }^{11}$ IC Waters system (Milford, MA, 119 USA) in conjunction with the Millennium 32 was used for the chemical evaluation of the water samples. This system contains a 616 pump with a $600 \mathrm{~S}$ controller and an Anion HR-Pak IC column $4.6 \times 75$ mm, an autosampler (717 plus), and a conductivity detector $432 .{ }^{11}$

\section{Assessment of Caries in Children}

\section{Study Population}

Lebanese children aged 5 and 12 years were recruited between January and June 2017 from four schools in Tripoli. Tripoli is the second largest city in Lebanon divided socioeconomically into four regions: Ebbe (low level), Abi Samra (middle level), Old city (low level), and New city (medium and high level). ${ }^{12}$ Schools were chosen randomly for each region of the city through a draw, among the list of institutions, provided by the Ministry of Education. Children were selected randomly from each school in each region.

Lebanese children aged 5 and 12 years, living in school region for at least 5 years, with written informed consent and completed questionnaire by parents, who consume only one source of water (tap or bottled), were included in the study. Those who are not permanent residents of the school region or who consume both tap water and bottled water were excluded.

\section{Clinical Oral Examination}

The caries index was recorded in a population of children in the four different socioeconomic regions of Tripoli. The evaluation of the caries index was performed using Klein and Palmer index for permanent (DMFT) and deciduous teeth (dmft)., ${ }^{713}$ Individual oral examinations were performed in classroom. One postgraduate student in Pediatric Dentistry Department of Saint Joseph University of Beirut conducted all the examinations according to WHO requirements. ${ }^{7}$ Artificial light, equipment (gloves, mask, and gauze pads), and prepackaged sterilized instruments (single use mirror and probe) were used for the oral examinations. The number of teeth with carious lesions at D1 level according the Eckstrand classification, ${ }^{13}$ teeth with fillings and missing teeth were recorded. The DMFT/dmft indices were calculated for dental caries experience assessment according to the WHO criteria. ${ }^{7}$

\section{Questionnaire}

A questionnaire intended for parents provides information concerning their children on demographic data (age, gender, and permanent residential address), the source of water consumed by children (tap or bottled), the possibility of consumption of fluoride supplements (yes/no), fluoridated salt (yes/no), daily toothbrushing (yes/no), daily consumption of tea (yes/no), and daily consumption of sweets (yes/no) in these children. The quantity of fluoride taken from water measured was also analyzed.

\section{Statistical Analyses}

Statistical analyses were performed using IBM SPSS Statistics (version 20). The level of significance was set at $p$ value $\leq 0.05$. Kolmogorov-Smirnov tests were used to assess the normality distribution of continuous variables. Paired Student $t$ tests were applied for the comparison of fluoride concentration between distribution points and sources and between June and November. One-sample $t$ tests were performed for the comparison of fluoride concentration in sources and distribution points with the optimal amount of fluoride recommended by the WHO for decay prevention $(0.5-1 \mathrm{mg} / \mathrm{L}) .^{14}$

In order to explore the explanatory variables associated with DMFT and dmft indices as the dependent continuous variable, univariate analyses followed by multivariate analyses were performed. Univariates analyses included Pearson correlation coefficient to assess the relationship between continuous variables (DMFT/dmft and fluoride concentrations in water), Student $t$-tests, and Mann-Whitney $U$ test for the comparisons of continuous variables between two groups and analysis of variance followed by Tukey post hoc tests for the comparison of continuous variables between three groups. Explicative variables with a $p$ value $<0.200$ in univariate analyses were included for multiple regression analyses. The collinearity assumption was tested, and variables highly correlated with each other were not included in the same model. Since variables tap or bottled water, place of residency, and fluoride concentration in water were highly correlated, and only the variable tap/bottled water were retained in the model. 


\section{Results}

\section{Assessment of Fluoride Concentrations}

The average concentration of fluoride at the distribution points during the month of June $(0.37 \pm 0.068 \mathrm{mg} / \mathrm{L})$ was significantly smaller compared to the sources $(0.44 \pm 0.075 \mathrm{mg} / \mathrm{L})$ ( $p$ value $=0.002$ ). However, the average concentration of fluoride at the distribution points during November $(0.43 \pm 0.117 \mathrm{mg} / \mathrm{L})$ was not significantly different than sources $(0.44 \pm 0.143 \mathrm{mg} / \mathrm{L})$ ( $p$ value $=0.772$ ). Fluoride concentration in bottled water varied between 0.03 and $0.25 \mathrm{mg} / \mathrm{L}$, and the mean concentration $(0.14 \pm 0.698$ $\mathrm{mg} / \mathrm{L}$ ) was significantly smaller compared to tap water sources and distribution points ( $p$ value $<0.001$ ).

The fluoride concentration in tap water in June $(0.44 \pm 0.075$ $\mathrm{mg} / \mathrm{L})$ and November $(0.44 \pm 0.143 \mathrm{mg} / \mathrm{L})$ and in the distribution points in November $(0.43 \pm 0.117 \mathrm{mg} / \mathrm{L})$ was not significantly different from the optimal concentration recommended by the WHO for decay prevention $(0.5-1 \mathrm{mg} / \mathrm{L}$ ) ( $p$ value $>0.05$ ). In contrast, the average amount of fluoride observed in the distribution points in June $(0.37 \pm 0.068 \mathrm{mg} / \mathrm{L})(p$ value $=0.001)$ and in bottled water $(0.14 \pm 0.698 \mathrm{mg} / \mathrm{L})$ ( $p$ value $<0.001)$ were significantly lower than the optimal amount of fluoride recommended by the WHO for decay prevention $(0.5-1 \mathrm{mg} / \mathrm{L}) .^{14}$

\section{Description of the Study Population}

Four hundred and two children aged 5 and 12 years were included in the study: 201 participants aged 12 years (104 boys and 97 girls) and 201 participants aged 5 years (102 boys and 99 girls). Concerning the distribution of the participants, 50,51,50, and 50 children aged 5 years were recruited from Abi Samra, Old city, Ebbe, and New city, respectively. In all, 50, 51, 50, and 50 children aged 12 years were recruited from Abi Samra, Old city, Ebbe, and New city, respectively.

Fluoride supplements were consumed by $21.9 \%$ of 5 -year-old children and by $13.4 \%$ of 12 -year-old children. Solely, $42.8 \%$ of 5 -year-old children and $50.2 \%$ of 12 -year-old children regularly brush their teeth at least once per day. This could explain the high prevalence of decay among 5-year-old (90.5\%) and 12-year-old (89.6\%) children. On the other hand, $51.7 \%$ of total children included in the study drank bottled water. Most children from low-income regions (Ebbe, Old city) drink tap water which contains more amount of fluoride than the bottled water consumed by most children from middle- and high-income regions (Abi Samra, New city) ( $p$ value $<$ 0.001). Sociodemographic characteristics of the participants, food, and fluoride consumption are illustrated in Table 1.

\section{Factors Associated with Caries Indices in Children}

DMFT and dmft were not significantly associated to the gender of children aged 5 years ( $p$ value $=0.342$ ) and 12 years ( $p$ value $=0.342$ ) (Table 2). However, a significant association was found between caries indices and the source of water consumed by children ( $p$ value $<0.001$ ); decay was significantly elevated for children drinking from bottled water compared to children drinking from tap water (Table 2).

A significant correlation was also found between fluoride concentration in water and carious indices ( $p$ value $<0.05)(r=$ -0.330 for DMFT and $r=-0.354$ for $\mathrm{dmft}$ ); DMFT/dmft indices increase significantly when fluoride intake decreases (Table 3).

This could explain the fact that decay indices were significantly related to the place of residency in Tripoli ( $p$ value $<0.001$ ); decay was significantly more elevated in high-income regions drinking frequently from bottled water ( $91.5 \%$ of Abi Samra and the new
Table 1: Characteristics of the study population according to age

\begin{tabular}{|c|c|c|c|}
\hline & & Frequency & Percentage \\
\hline \multirow[t]{19}{*}{ 5-year-old } & Gender & & \\
\hline & Boys & 102 & 50.7 \\
\hline & Girls & 99 & 49.3 \\
\hline & Source of water & & \\
\hline & Tab & 97 & 48.3 \\
\hline & Bottle & 104 & 51.7 \\
\hline & Caries prevalence & & \\
\hline & Presence & 182 & 90.5 \\
\hline & Absence & 19 & 9.5 \\
\hline & Tea consumption & 33 & 16.4 \\
\hline & $\begin{array}{l}\text { Fluoride supplements } \\
\text { intake }\end{array}$ & 44 & 21.9 \\
\hline & Teeth brushing & 86 & 42.8 \\
\hline & Sweet consumption & 154 & 76.6 \\
\hline & Fluoridated salt intake & 15 & 7.5 \\
\hline & Residence & & \\
\hline & $\begin{array}{l}\text { Abi Samra (middle- } \\
\text { income) }\end{array}$ & 50 & 24.9 \\
\hline & Old city (low-income) & 51 & 25.4 \\
\hline & Ebbe (low-income) & 50 & 24.9 \\
\hline & $\begin{array}{l}\text { New city (middle/high- } \\
\text { income) }\end{array}$ & 50 & 24.9 \\
\hline \multirow[t]{19}{*}{ 12-year-old } & Gender & & \\
\hline & Boys & 104 & 51.7 \\
\hline & Girls & 97 & 48.3 \\
\hline & Source of water & & \\
\hline & Tab & 97 & 48.3 \\
\hline & Bottle & 104 & 51.7 \\
\hline & Caries prevalence & & \\
\hline & Presence & 180 & 89.6 \\
\hline & Absence & 21 & 10.4 \\
\hline & Tea consumption & 48 & 23.9 \\
\hline & $\begin{array}{l}\text { Fluoride supplements } \\
\text { intake }\end{array}$ & 27 & 13.4 \\
\hline & Tooth brushing & 101 & 50.2 \\
\hline & Sweet consumption & 160 & 79.6 \\
\hline & Fluoridated salt intake & 18 & 9.0 \\
\hline & Residence & & \\
\hline & $\begin{array}{l}\text { Abi Samra (middle- } \\
\text { income) }\end{array}$ & 50 & 24.9 \\
\hline & Old city (low-income) & 51 & 25.4 \\
\hline & Ebbe (low-income) & 50 & 24.9 \\
\hline & $\begin{array}{l}\text { New city (middle/high- } \\
\text { income) }\end{array}$ & 50 & 24.9 \\
\hline
\end{tabular}

city) compared to low-income regions drinking frequently from tap water ( $87.62 \%$ of old city and Ebbe) (Table 2$)$.

Moreover, mean decay indices were significantly elevated in participants who do not daily brush their teeth compared to those who brush their teeth (DMFT: $p$ value $=0.014 ; \mathrm{dmft}: p$ value $<0.001$ ) (Table 4).

Also, sweet consumption was significantly associated with DMFT ( $p$ value $<0.001$ ) and dmft ( $p$ value $<0.001$ ); caries was 
Fluoride Intake and Caries

Table 2: Univariate analyses of the factors associated with decay indices in children

\begin{tabular}{|c|c|c|c|c|c|c|}
\hline & Explicative variables & & $n$ & Mean & Std deviation & $p$ \\
\hline \multirow[t]{18}{*}{ DMFT } & Gender & Boys & 104 & 3.38 & 1.691 & 0.342 \\
\hline & & Girls & 97 & 3.15 & 1.734 & \\
\hline & Source of water & Tap & 97 & 2.69 & 1.523 & $<0.001$ \\
\hline & & Bottled & 104 & 3.82 & 1.705 & \\
\hline & Teeth brushing & Yes & 101 & 3.12 & 1.84 & 0.198 \\
\hline & & No & 100 & 3.43 & 1.565 & \\
\hline & Tea consumption & Yes & 48 & 2.38 & 1.539 & $<0.001$ \\
\hline & & No & 153 & 3.56 & 1.67 & \\
\hline & Fluoride supplements & Yes & 27 & 2.96 & 1.87 & 0.312 \\
\hline & & No & 174 & 3.32 & 1.686 & \\
\hline & Sweets consumption & Yes & 160 & 3.54 & 1.625 & $<0.001$ \\
\hline & & No & 41 & 2.22 & 1.651 & \\
\hline & Fluoridated salt & Yes & 18 & 2.5 & 1.855 & 0.044 \\
\hline & & No & 183 & 3.35 & 1.683 & \\
\hline & Residence & Abi Samra & 50 & $3.54^{\mathrm{b}}$ & 1.717 & 0.048 \\
\hline & & Old city & 51 & $2.86^{\mathrm{a}}$ & 1.523 & \\
\hline & & Ebbe & 50 & $3.04^{\mathrm{a}}$ & 1.653 & \\
\hline & & New city & 50 & $3.66^{\mathrm{b}}$ & 1.858 & \\
\hline \multirow[t]{18}{*}{$\mathrm{dmft}$} & Gender & Boys & 102 & 4.29 & 3.062 & 0.342 \\
\hline & & Girls & 99 & 4.72 & 3.229 & \\
\hline & Source of water & Tap & 97 & 3.26 & 2.329 & $<0.001$ \\
\hline & & Bottled & 105 & 5.66 & 3.366 & \\
\hline & Teeth brushing & Yes & 86 & 3.22 & 2.313 & $<0.001$ \\
\hline & & No & 114 & 5.46 & 3.346 & \\
\hline & Tea consumption & Yes & 33 & 3.00 & 2.121 & 0.002 \\
\hline & & No & 168 & 4.8 & 3.233 & \\
\hline & Fluoride supplements & Yes & 44 & 4.75 & 2.479 & 0.556 \\
\hline & & No & 157 & 4.43 & 3.311 & \\
\hline & Sweets consumption & Yes & 154 & 5.29 & 3.078 & $<0.001$ \\
\hline & & No & 47 & 1.94 & 1.647 & \\
\hline & Fluoridated salt & Yes & 15 & 2.67 & 2.469 & 0.018 \\
\hline & & No & 186 & 4.65 & 3.152 & \\
\hline & Residence & Abi Samra & 50 & $5.34^{b}$ & 3.921 & 0.020 \\
\hline & & Old city & 51 & $3.59^{\mathrm{a}}$ & 2.594 & \\
\hline & & Ebbe & 50 & $3.92^{\mathrm{a}}$ & 2.709 & \\
\hline & & New city & 50 & $5.18^{\mathrm{b}}$ & 2.898 & \\
\hline
\end{tabular}

${ }^{\mathrm{a}, \mathrm{b}}$ Different letters indicate a significant difference according to Tukey post hoc tests

Table 3: Correlation between fluoride concentrations in water and decay indices

\begin{tabular}{llll}
\hline & & DMFT & $d m f t$ \\
\hline Fluoride concentrations in water & $\begin{array}{l}\text { Correlation } \\
\text { coefficient }\end{array}$ & -0.330 & -0.354 \\
& $p$ & 0.000 & \\
& $n$ & 201 & 0.000 \\
\hline
\end{tabular}

significantly higher among participants who eat candy (Table 4). The tea consumption was significantly related to DMFT ( $p$ value $<$ 0.001 ), but this was not the case with $\mathrm{dmft}$ ( $p$ value $=0.070$ ); the mean indices on permanent teeth was significantly lower among participants who drink tea compared to others that do not consume tea (Table 4).
Furthermore, fluoridated salt intake was significantly associated with DMFT ( $p$ value $=0.046)$ and $\mathrm{dmft}(p$ value $=0.033)$. The average carious index was significantly lower when salt was used (Table 4). However, a significant association between fluoride oral supplement intake and carious indices was not found for permanent ( $p$ value $=0.312)$ and deciduous teeth $(p$ value $=0.556)($ Table 2$)$.

\section{Discussion}

The primary objective was to evaluate fluoride concentration in water, the main source of systemic fluoride. Two water sources were evaluated: tap and bottled water, to cover all the sources of water consumed in Tripoli city. Different chemical methods were used to measure the concentration of fluoride in water: colorimetry, spectrophotometry, potentiometer and selective ion electrode. ${ }^{15}$ 
Fluoride Intake and Caries

Table 4: Multiple regression analyses of explicative variables associated with decay indices

\begin{tabular}{|c|c|c|c|c|c|c|c|c|}
\hline & \multirow[b]{2}{*}{ Model } & \multicolumn{2}{|c|}{ Unstandardized coefficients } & \multirow{2}{*}{$\begin{array}{l}\text { Standardized } \\
\text { coefficients } \\
\text { Beta }\end{array}$} & \multirow[b]{2}{*}{$t$} & \multirow[b]{2}{*}{ Sig. } & \multicolumn{2}{|c|}{$95.0 \%$ confidence interval for $B$} \\
\hline & & $B$ & Std. error & & & & Lower bound & Upper bound \\
\hline \multirow[t]{5}{*}{ DMFT } & Source of water & 1.348 & 0.226 & 0.394 & 5.956 & 0.000 & 0.901 & 1.794 \\
\hline & Tea consumption & 0.938 & 0.243 & 0.234 & 3.863 & 0.000 & 0.459 & 1.417 \\
\hline & Teeth brushing & 0.555 & 0.224 & 0.163 & 2.476 & 0.014 & 0.113 & 0.998 \\
\hline & Sweet consumption & -1.023 & 0.268 & -0.241 & -3.817 & 0.000 & -1.551 & -0.494 \\
\hline & Fluoridated salt & 0.815 & 0.390 & 0.136 & 2.089 & 0.038 & 0.046 & 1.584 \\
\hline \multirow[t]{5}{*}{ dmft } & Source of water & 2.975 & 0.351 & 0.474 & 8.477 & 0.000 & 2.283 & 3.667 \\
\hline & Tea consumption & 0.814 & 0.447 & 0.096 & 1.820 & 0.070 & -0.068 & 1.695 \\
\hline & Teeth brushing & 2.469 & 0.360 & 0.389 & 6.865 & 0.000 & 1.760 & 3.179 \\
\hline & Sweet consumption & -2.076 & 0.423 & -0.280 & -4.907 & 0.000 & -2.911 & -1.242 \\
\hline & Fluoridated salt & 1.394 & 0.650 & 0.117 & 2.145 & 0.033 & 0.112 & 2.675 \\
\hline
\end{tabular}

In this study, the chosen technique was ion chromatography because it is recommended by the WHO for the measurement of the fluoride content in water, and it is used in many recent studies. ${ }^{13,16,17}$

Chemical evaluations were carried out during the months of June (after the rain) and November (before the rain) to avoid the biases related to the climate variations. ${ }^{18}$ However, we did not find significant differences between average fluoride concentration between June and November. This study was the first to examine whether the rate of fluoride in the main sources varies after the domestic distribution of water. A decrease was noted between the average concentration of fluoride observed from sources $(0.44 \pm$ $0.075 \mathrm{mg} / \mathrm{L})$ and after home distribution $(0.37 \pm 0.068 \mathrm{mg} / \mathrm{L})$ for the month of June; further studies should be performed to confirm our findings.

The average fluoride concentration in our study in tap water was lower than the average fluoride concentration in Iranian tap water $(0.65 \pm 0.38 \mathrm{mg} / \mathrm{L})$; however, they were higher than those found in the United Arab Emirates (UAE) (ranging between 0.04 and $0.3 \mathrm{mg} / \mathrm{L}$ ). ${ }^{19}$ Other countries such as Tunisia, China, and India have greater variations of fluoride concentrations in tap water, ranging from 0 to $2.4 \mathrm{mg} / \mathrm{L}, 0.30$ to $15.24 \mathrm{mg} / \mathrm{L}$, and 0.5 to $8.5 \mathrm{mg} / \mathrm{L}$, respectively. ${ }^{20-22}$

Regarding bottled water, three bottles with different batches were collected for each brand, to cover the different seasonal fluctuations, which can influence the rate of fluoride in the water. ${ }^{16}$ A previous study in Lebanon showed a low average fluoride concentration in 32 brands of bottled water $(0.15 \mathrm{mg} / \mathrm{L}) .^{23}$ This could be explained by the fact Lebanese law does not impose to add any amount of fluoride in water. Similar results were found in bottled water consumed in UAE $(0.14 \mathrm{mg} / \mathrm{L})$, India $(0.2 \mathrm{mg} / \mathrm{L})$, and Australia $(<0.08 \mathrm{mg} / \mathrm{L}){ }^{15,16,24}$ Higher concentrations were observed in bottled water, consumed in Saudi Arabia, ranging from 0.5 to $0.83 \mathrm{mg} / \mathrm{L}^{25}$

The WHO recommends a minimum fluoride concentration of $0.5 \mathrm{mg} / \mathrm{L}$ to prevent tooth decay, not to exceed $1 \mathrm{mg} / \mathrm{L} .{ }^{14}$ The dose of fluoride added to water in a fluoridation program varies between countries. The Canadian dental association affirms the need for additional studies to define the optimal rate of fluoride in water. ${ }^{26}$ Given the disparity of the recommended optimum rate of fluoride in water worldwide, and since fluoride concentration in tap water has a considerable average close to $0.5 \mathrm{mg} / \mathrm{L}$ in most sources as revealed in our findings, we decided to evaluate the explanatory variables associated with caries indices of children from different regions in Tripoli taking into consideration the source of water consumed.
The main objective of this second phase of the project was to compare caries index related to the amount of fluoride provided by water to evaluate the effectiveness of the fluoride content in tap water. Our study considered two age-groups: 5 and 12 years old. In fact, decay level should be examined at age of 5 , since changes over short periods can occur in deciduous teeth compared to permanent teeth. On the other hand, the age of 12 is considered as an indicator for international comparisons and disease surveillance. ${ }^{7}$

According to our study, $76 \%$ of Ebbe children and $99 \%$ in Old City consume tap water. In fact, the modest socioeconomic level of these regions forces people to use tap water, which is already available in their homes. On the contrary, $100 \%$ of children in the new city and $83 \%$ in Abi Samra, whose socioeconomic level is medium or high, prefer to consume bottled water. The substitution of drinking water by bottled water is also observed worldwide, as consumers give greater confidence to bottled regarding purity and absence of contaminants. ${ }^{27}$

A close relationship between the caries index and the source of water consumed is present in our study. The presence of fluoride in tap water has contributed to a significant reduction in the caries index in children from distressed regions, compared to those who consume bottled water in the affluent regions even though the modest socioeconomic level is considered a carious risk factor by the international guidelines. ${ }^{28}$

A nationwide study in Lebanon revealed a mean caries index of 5.15 for the deciduous teeth and 3.42 for 12 -year-old children. ${ }^{8}$ This result is close to our study for the region of Abi Samra ( $\mathrm{dmft}$ 5.34, DMFT 3.54) and new city (dmft 5.18, DMFT 3.66), but it is higher than the indices found in Ebbe (dmft 3.92, DMFT 3.04) and old city (dmft 3.59, DMFT 2.86). Comparing to national rates, lower decay rates are observed in deciduous and permanent dentitions only in regions benefiting from fluoride in drinking water.

The WHO has set goals to be achieved at the beginning of the 21 st century to improve oral health. The first goal is to reduce to $50 \%$ the number of children between the age of 5 and 6 who do not have any decay. The second goal is to reach an average DMFT index of 3-for 12-year-old children. ${ }^{7}$

Our study showed that the presence of fluoride in tap water with concentrations close to $0.5 \mathrm{mg} / \mathrm{L}$ reduced the caries index, which made reaching the targets of WHO for 12-year-olds possible. However, this concentration seems to be insufficient in children from 5 to 6 years: only $11.76 \%$ of the children of the old city, $10.2 \%$ of Ebbe and Abi Samra, and $6.12 \%$ of the new city are free from decay. These results may be explained by some ignorance about 
oral health among parents, about deciduous teeth, the care of permanent teeth is more valued. Deciduous teeth are also more quickly affected by decay than permanent teeth. Thus, deciduous teeth require more preventive measures to fight tooth decay in this city. High prevalence is also observed among young children in several Arab and South Asian countries..$^{29-33}$ On the other hand, countries such as Sweden, Australia and United Kingdom have achieved the objectives of the FDI and WHO, as consequence of the implementation of preventive measures such as fluoridation. ${ }^{31}$

The secondary objectives of this study were to estimate the frequency of toothbrushing, sweets intake, and consumption of tea, salt, and fluoride oral supplements (other systemic sources of fluoride), and, as factors that may affect decay risk and to evaluate fluoride exposure in Tripoli to prevent the harmful effects of fluoride overdose on oral and general health.

The frequency of dental brushing was studied in this research. The results showed that daily brushing (at least once a day) has a protective effect on the teeth of 5-year-old children, which is in line with the international recommendations on this subject. ${ }^{34,35}$ This study shows a social inequality in brushing habits: children in affluent regions brush their teeth more frequently than children in distressed regions which is found in several other studies. ${ }^{34-36}$ Social inequality in dental brushing must be a major concern in national awareness campaigns on oral health. The results should help to improve instructions on brushing teeth to improve the oral situation in all especially in distressed areas.

High consumption of sweets among children in Tripoli is observed in the four regions where most children eat sweets at least twice a day between meals. Regular consumption of sweets between meals is the most important dietary factor in the development of dental caries. ${ }^{37}$ Oral health professionals need to become more involved in nutrition education to fight tooth decay. ${ }^{34,35}$ The Ministry of Health must set well-defined targets at the community level to reduce high sugar consumption.

More frequent tea consumption (in Ebbe and old city) was associated with lower DMFT. A previous study in Lebanon showed that tea has high average fluoride content (average of $0.955 \mathrm{mg} / \mathrm{L}$ ). ${ }^{10}$ Tea also contains polyphenol, which has an antibacterial effect and reduces acid production. Therefore, health professionals should encourage children with high carious risk to consume tea regularly in accordance with permitted caffeine standards for children (1 to 2 cups of tea per day)..$^{38}$

Some brands of fluoridated salt are available on the Lebanese market. The consumption of fluoride salt is low, ranging from 0 to $15 \%$ among children in Tripoli which can be attributed to the disagreement over salt fluoridation in Lebanon.

Fluoride supplementation consumption is more common in affluent regions and nonexistent in distressed regions. However, the association between fluoride oral supplement intake and carious indices was not significant for permanent and deciduous teeth. The difference in fluoride content in the water consumed between distressed and affluent regions could offset these results. Larger studies are needed to confirm this association, as there is disparity in results affecting the efficacy of fluoridated supplements and prevention of caries. $^{39}$

Our results deserve to be supplemented by additional studies with the same objectives and covering all regions of Lebanon. This is imperative to develop a fluoride policy at the national level, based on field data and clear and precise scientific evidence. The national health oral program should then be supported by learning effective oral hygiene methods and nutrition education about the harmful effects of sugar. Lastly, evaluation and systematic epidemiological surveillance should remain in place for Lebanese children.

\section{Conclusion}

This study highlights that the presence of fluoride concentrations close to $0.5 \mathrm{mg} / \mathrm{L}$ in most of tap water sources in Tripoli, has reduced the negative impact of the socioeconomic factor on oral health, although the brushing and consumption of fluoride supplements are more frequent in affluent regions. Benefit of tea was also observed in this study against tooth decay. Based on our results, pedodontists should take into consideration the source of water consumed by the patient before prescribing any fluoride supplementation in order to avoid overconsumption. They should promote effective oral hygiene methods, nutritional education, and encourage regular tea consumption as an affordable source of fluoride to prevent caries.

\section{ACKnOWLedgments}

We would like to thank the ministry of education and the national water of North Lebanon for their support we have received while conducting the study.

\section{Ethical Approval}

The protocol was submitted to the ethics committee of Saint-Joseph University of Beirut, Lebanon (USJ-2017-127).

\section{References}

1. Kassis A, El Osta N, Tubert-Jeannin S, et al. Cross-cultural adaptation and validation of the child perceptions questionnaire (CPQ11-14) among children in Lebanon. BMC Oral Health 2018;18(1):18. DOI: 10.1186/s12903-018-0482-x.

2. Pahel BT, Rozier RG, Slade GD. Parental perceptions of children's oral health: the early childhood oral health impact scale (ECOHIS). Health Qual Life Outcomes 2007;5(1):6. DOI: 10.1186/1477-7525-5-6.

3. Mount GJ, Hume WR. Preservation and restoration of tooth structure. 2nd ed., Brighton (Australia): Knowledge Books and Software; 2005.

4. Armfield JM. Community effectiveness of public water fluoridation in reducing children's dental disease. Public Health Rep 2010;125(5): 655-664. DOI: 10.1177/003335491012500507.

5. Murthy VH. Surgeon general's perspectives. Public Health Rep 2015;130(3):1-3. DOI: 10.1177/003335491513000303.

6. Petersen $\mathrm{PE}, \mathrm{Ogawa} \mathrm{H}$. Prevention of dental caries through the use of fluoride-the WHO approach. Commun Dent Health 2016;33:66-68.

7. Petersen PE. The world oral health report 2003: continuous improvement of oral health in the 21st century--the approach of the WHO global oral health programme. Commun Dent Oral Epidemiol 2003;31(Suppl 1):3-23. DOI: 10.1046/j.2003.com122.x.

8. Doumit M. Dental caries and fluorosis among children in Lebanon. J Oral Health Craniofac Sci 2017. 001-008.

9. Doumit M, Baez R, Oral Health Programme In Lebanon: Technical assistance provided for development of baseline studies for salt fluoridation. 2004.

10. Jurdi M, Kambris M. Decision to fluoridate 1. Fluoride levels in herbal teas used in Lebanese communities. Food Nutr Bull 2001;22(1):62-65. DOI: $10.1177 / 156482650102200110$.

11. Fawell JBK, Chilton J, Dahi E, et al. Fluoride in drinking-water. WHO; 2006.

12. L'eau en société KM, Pratiques et perceptions des usagers à l'égard du service public en charge de la distribution de l'eau potable et de l'assainissement à Tripoli 2007. République Libanaise Etablissement des Eaux du Liban Nord. http://www.corail-developpement.org/ 
docs/les_references/Etude_Usagers_Tripoli_2007.pdf. Last Access 2019.

13. Shivakumar K, Prasad S, Chandu G. International caries detection and assessment system: a new paradigm in detection of dental caries. J Conserv Dent 2009;12(1):10-16. DOI: 10.4103/0972-0707. 53335.

14. Word Health Organization. Guidelines for drinking-water quality. Incorporating the First Addendum. 4th ed., Geneva 2017.

15. Walia T, Abu Fanas S, Akbar M, et al. Estimation of fluoride concentration in drinking water and common beverages in United Arab Emirates (UAE). Saudi Dent J 2017;29(3):117-122. DOI: 10.1016/ j.sdentj.2017.04.002.

16. Cochrane $\mathrm{N}$, Hopcraft $\mathrm{M}$, Tong $\mathrm{A}$, et al. Fluoride content of tank water in Australia. Aust Dent J 2014;59(2):180-186. DOI: 10.1111/adj. 12163.

17. Abouleish MY. Evaluation of fluoride levels in bottled water and their contribution to health and teeth problems in the United Arab Emirates. Saudi Dent J 2016;28(4):194-202. DOI: 10.1016/ j.sdentj.2016.08.002.

18. Grobler SR, Dreyer AG, Blignaut RJ. Drinking water in South Africa: implications for fluoride supplementation. SADJ 2001;56: 557-559.

19. Taghipour N, Amini H, Mosaferi M, et al. National and subnational drinking water fluoride concentrations and prevalence of fluorosis and of decayed, missed, and filled teeth in Iran from 1990 to 2015: a systematic review. Environ Sci Pollut Res Int 2016;23(6):5077-5098. DOI: 10.1007/s11356-016-6160-0.

20. Guissouma W, Hakami O, Al-Rajab AJ, et al. Risk assessment of fluoride exposure in drinking water of Tunisia. Chemosphere 2017;177: 102-108. DOI: 10.1016/j.chemosphere.2017.03.011.

21. Zhang L, Huang D, Yang J, et al. Probabilistic risk assessment of Chinese residents' exposure to fluoride in improved drinking water in endemic fluorosis areas. Environ Pollut 2017;222:118-125. DOI: 10.1016/j.envpol.2016.12.074.

22. Arif $M$, Husain I, Hussain J, et al. Assessment of fluoride level in groundwater and prevalence of dental fluorosis in Didwana block of Nagaur district, Central Rajasthan, India. Int J Occup Environ Med 2013;4:178-184

23. Semerjian LA. Quality assessment of various bottled waters marketed in Lebanon. Environ Monit Assess 2011;172(1-4):275-285. DOI: 10.1007/ s10661-010-1333-7.

24. Thippeswamy HM, Kumar N, Anand SR, et al. Fluoride content in bottled drinking waters, carbonated soft drinks and fruit juices in Davangere city, India. Indian J Dent Res 2010;21(4):528-530. DOI: 10.4103/0970-9290.74206
25. Aldrees AM, Al-Manea SM. Fluoride content of bottled drinking waters available in Riyadh, Saudi Arabia. Saudi Dent J 2010;22(4):189-193. DOI: 10.1016/j.sdentj.2010.07.003.

26. Canadian Dental Association. CDA position on use of fluorides in caries prevention. 2015.2-5. http://www.cda-adc.ca/_files/position_ statements/fluoride.pdf.

27. Ahiropoulos V. Fluoride content of bottled waters available in Northern Greece. Int J Paediatr Dent 2006;16(2):111-116. DOI: 10.1111/j.1365-263X.2006.00702.x.

28. Policy on early childhood caries (ECC): unique challenges and treatment options. Pediatr Dent 2017;39:62-63.

29. El-Nadeef MA, Hassab H, Al-Hosani E. National survey of the oral health of 5-year-old children in the United Arab Emirates. East Mediterr Health J 2010;16(01):51-55. DOI: 10.26719/2010.16.1.51.

30. Al-Malik MI, Holt RD, Bedi R. Prevalence and patterns of caries, rampant caries, and oral health in two- to five-year-old children in Saudi Arabia. J Dent Child (Chic) 2003;70:235-242.

31. Azizi Z. The prevalence of dental caries in primary dentition in 4to 5-year-old preschool children in northern Palestine. Int J Dent 2014;2014:839419. DOI: 10.1155/2014/839419.

32. Al-Mutawa SA, Shyama M, Al-Duwairi Y, et al. Dental caries experience of Kuwaiti kindergarten schoolchildren. Commun Dent Health 2010;27:213-217.

33. Duangthip D, Gao SS, Lo EC, et al. Early childhood caries among 5 - to 6-year-old children in Southeast Asia. Int Dent J 2017;67(2):98-106. DOI: $10.1111 /$ idj.12261.

34. American Academy of Pediatric Dentistry Council on Clinical Affairs. Policy on dietary recommendations for infants, children, and adolescents. Pediatr Dent 2017;39:64-66.

35. Kastorini CM, Critselis E, Zota D, et al. Greek national dietary guidelines scientific team. national dietary guidelines of Greece for children and adolescents: a tool for promoting healthy eating habits. Public Health Nutr 2019;22(14):2688-2699. DOI: 10.1017/S1368980019001034.

36. Bast LS, Nordahl H, Christensen LB, et al. Tooth brushing among 11- to 15-year-olds in Denmark: combined effect of social class and migration status. Community Dent Health 2015;32:51-55.

37. Sheiham A, James WP. A reappraisal of the quantitative relationship between sugar intake and dental caries: the need for new criteria for developing goals for sugar intake. BMC Public Health 2014;14(1):863. DOI: $10.1186 / 1471-2458-14-863$.

38. Goenka P, Sarawgi A, Karun V, et al. Camellia sinensis (tea): Implications and role in preventing dental decay. Pharmacogn Rev 2013;7(14): 152-156. DOI: 10.4103/0973-7847.120515.

39. Tomasin L, Pusinanti L, Zerman N. The role of fluoride tablets in the prophylaxis of dental caries. A literature review. Ann Stomatol (Roma) 2015;6:1-5. DOI: 10.11138/ads/2015.6.1.001. 